\title{
Precision of 3D MSCT Scan Diagnostcs on Maxillofacial Trauma Compared to Stabilization and Instrumentation Operation Results
}

\author{
Meitty Christina Hidayati ${ }^{1}$, Anggraini Dwi Sensusiati ${ }^{1}$, Hari Basuki ${ }^{1}$ \\ ${ }^{I}$ Department of Radiology, Faculty of Medicine, Universitas Airlangga-Dr. Soetomo General Hospital, \\ Surabaya 60285, Indonesia
}

\begin{abstract}
Handling standardized radiological readings of patients with maxillofacial trauma, particularly in radiology are currently absent. Appropriate and accurate of radiological reading results could be as the guideline for surgeons in determining surgical procedures. This study aimed to evaluate the diagnostic accuracy of maxillofacial fracture patients with head 3D CT scan compared to stabilization and instrumentation results as gold standard. Secondary data that derived from medical records were used as 29 patients with clinical maxillofacial trauma enrolled in this study at Radiology Section of Dr.Soetomo General Hospital from November 2012 to March 2013. The Mc Nemar test showed that there was no significant difference between the 3D CT scan results and the stabilization also instrumentation results with $p=1.000(p>0.05)$. While, the result was by calculating Kappa coefficient that a high suitability between head 3D CT scans and stabilization also instrumentation result with $\kappa=1.000, p=0.000(p<0.05)$. There were several complications in the form of Cranii Bone Fraktur (25\%), intracranial complication (15.24\%), Haematosinus $(52.38 \%)$ and Soft tissue haematoma (32.38\%) with most intracranial complications ICH $(31.25 \%)$, then, most soft tissue complications were in the Orbita region (26.47\%) and the most common Haematosinus complications regarding Sinus Ethmoid and Maksilaris (29.09\%). It concluded that the 3D CT scan results were in accordance with the results of stabilization and instrumentation operations.
\end{abstract}

Keywords: Maxillofacial Trauma, Head Ct Scan, Head 3D Scan, Stabilization Operation

\section{Introduction}

Handling standardized radiological readings of patients with maxillofacial trauma, particularly in radiology are currently absent. This standardization is of crucial importance because it affects the diagnostic accuracy, especially in trauma cases. Appropriate and accurate of radiological reading results could be as the guideline for surgeons in determining surgical procedures. Radiology examination was originally a head photograph, which is expected to evaluate the presence of fractures and some of the complications, but in cases of maxillofacial fracture, the modalities complexity has much deficiency because of it unevaluated the bones in an overlapping state ${ }^{1}$.

\section{Corresponding Author:}

Anggraini Dwi Sensusiati

anggrainidwifkunair@yahoo.com
CT Scan is used as an evaluation of trauma cases with an excess of axial reformated sagittal and coronal slices, MPR and 3D reconstruction that could evaluate anatomical structures more broadly and in detail. It could evaluate the state of the fracture to the size of $<2 \mathrm{~cm}$, soft tissue, compartments that are regulated in craniomaxillofacial and evaluated the complications from intracranial hemorrhage to the presence of cranial also cervical fractures. Images of CT scan could be rotated, split, also anatomical structures could be separated and individual images of different tissue types could be generated. 3D images provide an overall spatial concept that allows a better understanding of the complexity of some 2D axial. 3D CT scan we are able to focus on specific areas of clinical and surgical concern. We could easily appreciate the postoperative improvement of possible complications. 3D reconstruction is useful in visualizing bone fragments from all points of view, not only the fracture fragments but suggestions of the 
mechanism of injury could easily assess. In addition, 3D CT scan reform has helped many patients with maxillofacial fractures ${ }^{2}$.

This is in accordance with research conducted by Johnson and Feuerbach (2011) that stated by using conventional photos of bone trauma are technically difficult and only small information could be obtained. However, by using MSCT 3D with the volume rendering technique on fracture patients, it could be seen complex anatomical images such as facial bones from various orientations. A 3D MSCT image could make a better interpretation of difficult fracture than in CT cross-sectional image(Gillespie). 3D CT scans were performed on 100 patients with maxillofacial trauma, which $80 \%$ were male and $20 \%$ were female. Based on the etiology, road traffic accidents $(75 \%)$ is the most common, followed by the attack (16\%), decrease (7\%) and sports-related accidents (2\%), also 28 cases $(28 \%)$. Head 3D CT scans have a significant degree of accuracy in determining the final diagnosis and treatment plan for the maxillofacial fracture. The conclusions were head 3D CT scans particularly valuable in assessing cases of maxillofacial fractures with the severe injury, allowing a clear perception of the primary rate of fracture line and resulting in fragment displacement. Modality allows precise surgical analysis and surgical planning compared to conventional radiography in cases of maxillofacial fractures ${ }^{3-7}$.

Based on the description above, the authors were interested to evaluate the diagnostic accuracy of maxillofacial fracture patients with the examination of head 3D CT scan that compared to the results of stabilization and instrumentation operations as the gold standard.

\section{Method}

Twenty-nine patients with clinical maxillofacial trauma at Radiology Section of Dr.Soetomo General Hospital Emergency Unit from November 2012 to March 2013. Total sampling with inclusion criteria conducted in this study was: Head 3D CT scans of maxillofacial clinical trauma patients and undergo stabilization operation and instrumentation.

A retrospective observational study by using secondary data derived from medical records was used, while the collected nominal data was arranged in tabular form and analyzed descriptively by calculating the sensitivity, specificity, positive and negative predictive value also accuracy, followed by inferential analysis with Mc Nemar test and calculating Kappa coefficient.

\section{Results}

\section{Characteristics The Study Sample}

Twenty-nine subjects with maxillofacial trauma that consisting of 25 male (86.21\%) and 4 female $(13.79 \%)$ were obtained. There was a group of under 20 years old was $8(27.59 \%)$ patients, age group 20 - 30 years old was $8(27.59 \%)$ patients, age group $30-40$ years old was $7(24.14 \%)$ patients, age group 40-50 years old was 3 $(10.34 \%)$ patients, and age group above 50 years old was $3(10.34 \%)$ patients. The oldest was 52 years old while the youngest was 13 years old. From 29 patients, the injury was caused by traffic accident by $26(89.66 \%)$, fell by $2(6.90 \%)$, fights $(3.45 \%)$ and sports $(0 \%)$.

\section{Characteristics of Maxillofacial fractures}

Twenty-nine patients in this study were; who experienced a maxillofacial fracture was 27 (93.10\%) and non-fractured was $2(6.90 \%)$ (Table 1). Maxillofacial fractures were obtained on maxillofacial bone and zygoma bone $(21.25 \%)$ and incarceration of rice and tooth septum (1.25\%) (Table 1).

Table 1. Distribution of maxillofacial fractures according to affected bone

\begin{tabular}{|l|l|l|}
\hline Bones & Frequency & Percentase (\%) \\
\hline Frontal Bone & 7 & 8.75 \\
\hline Temporal Bone & 4 & 5.00 \\
\hline Parietal Bone & 3 & 3.75 \\
\hline Zygoma Bone & 17 & 21.25 \\
\hline Orbital Bone & 8 & 10.00 \\
\hline Nasal Bone & 6 & 7.50 \\
\hline Maxilla Bone & 17 & 21.25 \\
\hline Mandibular Bone & 14 & 17.50 \\
\hline Ethmoidal Sinuses & 2 & 2.50 \\
\hline Nasal Septum & 1 & 1.25 \\
\hline Teeth & 1 & 1.25 \\
\hline Total & 80 & 100.00 \\
\hline
\end{tabular}




\section{Characteristics of Orbital Bone Fracture}

The highest number of orbital segment fractures was on Supraorbital (27.27\%) and infrequently on Lasser wing and Greater wing $(0.00 \%)$ (Table 2).

Table 2. Characteristics of Fracture Segment Orbital

\begin{tabular}{|l|l|l|}
\hline Segments & Frequency & Percentase (\%) \\
\hline Frontal Process & 1 & 9.09 \\
\hline Supraorbital & 3 & 27.27 \\
\hline Temporoorbita & 0 & 0.00 \\
\hline Zygoma frontal process & 2 & 18.18 \\
\hline Maksiloorbita & 2 & 18.18 \\
\hline Lacrimal bone & 3 & 27.27 \\
\hline Lasser Wing & 0 & 0.00 \\
\hline Greater Wing & 0 & 0.00 \\
\hline Total & 18 & 100.00 \\
\hline
\end{tabular}

The most fractures obtained from the Zygoma Segments was on Orbital Process and Orbital Surface 12 (44.44\%) also infrequently was Zygomaticofacial foramen 1 (3.70\%). Meanwhile, fracture of Segment Zygoma mostly on left Frontal Process and Orbital Process was 8 cases.

\section{Characteristics of a Zygoma Segment Fracture by Type of Fracture}

The obtained fractures of the Zygoma Segment by Most Segmental Fracture Type was 53.33\%.

\section{Frontal Fracture}

Most Characteristics of Frontal segments Fracture was Frontal bone $(100 \%)$ and imprinted on the Peduncular plate $(0.00 \%)$. Most Frontal Fractures on Frontal bone on the left side was 5 cases. The most characteristics of Frontal Segment Fractures based on fracture type was Segmental Type (80\%).

\section{Nasal Bone Fracture}

Most nasal segment fractures were Nasal Bone characteristic $(75 \%)$ and inhibited Peduncular plate (0.00\%). Most Nasal Segment Fractures regarding Nasal Bone on both right and left side was 2 cases, while, most
Nasal Segment Fracture Based on Types of Fracture was Segmental Types (66.67\%).

\section{Maxilla Bone Fracture}

Most maxilla segment fracture distribution of Orbital surface 11 frequency $(27.50 \%)$ and infrequently on Temporal Process also Frontal Process 5 frequency $(12.50 \%)$. Most of the maxillary segmental fracture characteristics on left side orbital surface were 10 cases. While, most Fracture of the Maximum Segment by Type of fracture was segmental and communitive Type (43.75\%).

\section{Mandibular Bone Fracture}

The most characteristics of Mandibular segment fracture was Symphysis Mandibula (34.48\%), infrequently wasCondylar Process and Coronoid Process $(0.00 \%)$ (Table 3). Then, the most Mandibular Segment Fractures was Symphysis Mandibula on the right side were 7 cases. While, the most Fracture of Mandibular Segment by Type of Fracture was Segmental and Communitive Type (42.86\%).

Table 3. Characteristics of Mandibular Segment Fracture

\begin{tabular}{|l|l|l|}
\hline Segments & Frequency & $\begin{array}{l}\text { Percentase } \\
(\mathbf{\%})\end{array}$ \\
\hline Condylar Process & 0 & 0 \\
\hline Coroid Process & 0 & 0 \\
\hline RamusMandibula & 3 & 10.34 \\
\hline AngleMandibula & 4 & 13.79 \\
\hline BodyMandibula & 8 & 27.59 \\
\hline Alveola Process & 4 & 13.79 \\
\hline Symphysis Mandibula & 10 & 34.48 \\
\hline Total & 20 & 100 \\
\hline
\end{tabular}

\section{Special Classification of Maxillofacial Fracture}

Twenty-nine Orbita Fracture patients who experienced NOE type (Naso-Orbita-Ethmoidal) was 1 (3.45\%) and Blow Out Orbita was none The classification distribution of maxilla fracture type Le-Fort 1 was 4 people (13.79\%), Fracture Max type Le-Fort 2 and Le- 
Fort 3 was none. Two-types head fractures that excluded in the Maxillofacial Fracture group was Cranii Bone Fracture (25\%) and Occipital Fracture (75\%).

\section{Complications}

Characteristics of maxillofacial fractures according to the appear complications from 29 patients were intracranial complications 16 (15.24\%), Haematosinus
55 (52.38\%) and Soft tissue hematoma 34 (32.38\%). The most intracranial complications were ICH (31.25\%) and infrequently were $\operatorname{EDH}(0.00 \%)$ (Table 4$)$. Complications in the softest tissue was Orbita region (26.47\%) and infrequently was Parietal Region (2.94\%) (Table 5) The most common Haematosinus complications was Sinus Ethmoid and Maksilaris (29.09\%) also Nasopharynx (1.82\%). (Table 6)

Table 4. Distribution of intracranial complications

\begin{tabular}{|l|l|l|}
\hline Intracranial & Frequency & Percentase (\%) \\
\hline ICH & 5 & 31.25 \\
\hline IVH & 0 & 0.00 \\
\hline SAH & 3 & 18.75 \\
\hline EDH & 0 & 0.00 \\
\hline SDH & 2 & 12.50 \\
\hline Pneumatochele & 3 & 18.75 \\
\hline Difusaxional brain injury & 3 & 18.75 \\
\hline Total & 16 & 100 \\
\hline
\end{tabular}

Table 5. Distribution of complications in soft tissue

\begin{tabular}{|l|l|l|}
\hline Region & Frequency & Percentase (\%) \\
\hline Ocipital & 1 & 2.94 \\
\hline Frontal & 6 & 17.65 \\
\hline Temporal & 7 & 20.59 \\
\hline Parietal & 1 & 2.94 \\
\hline Orbital & 9 & 26.47 \\
\hline Nasal & 4 & 11.76 \\
\hline Fasialist & 6 & 17,65 \\
\hline Total & 34 & 100.00 \\
\hline
\end{tabular}


Table 6. Distribution of complications in haematosinus

\begin{tabular}{|l|l|l|}
\hline Sinus & Frequency & Percentase (\%) \\
\hline Maxillary & 16 & 29.09 \\
\hline Ethmoid Sinus & 16 & 29.09 \\
\hline Frontalis & 6 & 10.91 \\
\hline Sphenoid & 7 & 12.73 \\
\hline Nasal Cavum & 9 & 16.36 \\
\hline Nasopharynx & 1 & 1.82 \\
\hline Total & 55 & 100.00 \\
\hline
\end{tabular}

\section{Stabilization and instrumentation operations}

From 29 patients, stabilization action and instrumentation were performed in the form of closed reposition was 3 (6.25\%), open repositioning wiring was 15 (30.61\%), Open Repositioning plating was 23 (46.94\%) and Butterfly Gypsum was 7 (16.33\%).

\section{Comparison of MSCT Scan examination results and Stabilization also Instrumentation operations.}

All of the total subjects, only 14 subjects the researchers could get from the patient's medical records, from the 14 existing data with maxillofacial trauma, 3D CT Scan and result of stabilization and instrumentation operation were obtained. True Positive $(\mathrm{TP})=100 \%$, True Negative $(\mathrm{TN})=100 \%$, False Positive $(\mathrm{FP})=100 \%$, and False Negative $(\mathrm{FN}))=100 \%$. (Table 7).

Table 7. Results of Stabilization \& Instrumentation Operations

\begin{tabular}{|c|c|c|c|c|}
\hline & & \multicolumn{2}{|c|}{ Operation stabilization $\&$ instrumentation results } & \\
\hline & & Positive & Negative & \\
\hline \multirow{3}{*}{ 3D MSCT Scan } & Positive & 14 & 0 & 14 \\
\hline & Negative & 0 & 2 & 2 \\
\hline & & 27 & 2 & 29 \\
\hline
\end{tabular}

Mc. Nemar $\mathrm{p}=0.000$

Kappa $=1.000 \mathrm{p}=0.000$

The result of Mc Nemar test showed no significant difference between head 3D CT scans result and stabilization also instrumentation operation with $\mathrm{p}=$ $1,000(p>0.05)$. While the of the analysis by calculating Kappa coefficient shows that there was a high suitability between head 3D CT scans with stabilization and instrumentation result with $\kappa=1.000, p=0.000(\mathrm{p}$ $<0.05)$.

\section{Discussion}

A Head 3D CT Scan with Volume Rendering (VR) to display bone images in $3 \mathrm{D}$ reconstruction was used, while 3D reconstruction was considered as the best modality in looking at the anatomical structure of bone because it produces spatial resolution and builds a combination of ultra-thin submillimeter combinations of slices ${ }^{8,9}$.

In the study, the epidemiologic incidence of maxillofacial trauma was more common in male $(86.21 \%)$ than female $(13.79 \%)$ with the most in $<20$ years old group and 20-30 years old group (27.59\%). The mechanism of etiology injury was a traffic accident $(89.66 \%)$. This was in accordance with previous 
research which states that the incidence rate was higher in men (20-29y/o) with the etiology of traffic accidents, especially motorcycles.

The physical examination of the maxillofacial trauma patient was insufficient to maintain the maxillofacial fracture diagnostic, it still needs radiological examination. From a radiological examination that using a head 3D CT scan, it was found that patients with maxillofacial fractures $(93.1 \%)$ and had no fracture $(6.9 \%)$ with the most fractures occurring was in zygoma and maxillary bone $(21.25 \%)$. This was in accordance with the previous study that most fractures occur in the maxillary bone due to bustrecess in the maxillary region ${ }^{10,11,12}$.

Maxillofacial trauma results were; a severe variation injury, bruise, excoriation, various vulnus of soft tissues to fractures. Maxillofacial fractures only occur in one place or complex, due to impact with low strength or high strength ( $>50 \%$ gravitational forces). Maxillofacial fractures will unreleased from the head injury due to the location and adjacent structures. Maxillofacial structures were considered reducer due to trauma, thus to protect the intracranial structure ${ }^{13,14,15}$.

There were several complications in the form of Cranii Bone Fracture (25\%), intracranial complication (15.24\%), Haematosinus (52.38\%) and Soft tissue haematoma (32.38\%), the most intracranial complications was ICH (31.25\%), most soft tissue complications was in the Orbital region (26.47\%) and the most common Haematosinus complications was Sinus Ethmoid and Maxilla (29.09\%). This was in accordance with previous studies that stated, 253 maxillofacial fractures patients with the head injury was $20.2 \%$, maxillofacial fractures accompanied by intracranial hemorrhage was $28.3 \%$ in the upper third of the face while Maxillofacial fractures accompanied by a cranial fracture was $57.1 \%$.

\section{Conclusion}

The 3D CT scan results were compatible with the results of stabilization and instrumentation operations.

Ethical Clearance: The present study was carried out in accordance with the research principles. This study implemented the basic principle ethics of respect, beneficence, nonmaleficence, and justice.

Conflict of Interest: There is no report of conflict of interest involved with this study so far.

Source of Funding: This study is funded by authors' fund only without external funds or donation.

\section{References}

1. Deng K, Wu B, Sun J. [The value of threedimensional helical CT imaging in the diagnosis of maxillofacial fractures]. Hua xi yi ke da xue xue bao $=$ Journal of West China University of Medical Sciences = Huaxi yike daxue xuebao. 2001;32(1):123-5.

2. Morimoto Y, Tanaka T, Yamamoto N. New trends and advances in oral and maxillofacial imaging. Current Med Imag Reviews 2009;5:226-37.

3. Stack BC, Ruggiero FP. Maxillary and Periorbital Fractures. In: Bailey BJ, Johnson JT Newlands SD (eds.). Head \& Neck Surgery - Otolaryngology. Philadelphia: Lippincott Williams \& Wilkins; 2006. 976-92 p.

4. Wijayahadi RY, Murtedjo U, Reksoprawiro S, Marmowinoto RM, Sahudi, Susilo DHR. Trauma Maksilofasial Diagnosis dan Penatalaksanaanya, - Surabaya: SU dr.Soetomo/FK Universitas Airlangga; 2003.

5. Hansen JT, Lambert DR. Netter's Clinical Anatomy. New York: Elsevier; 2005.

6. Smith JE, Leach JL. Mandibular Fractures. Philadephia: Lippincott Williams \& Wilkins; 2006. $.962-73 \mathrm{p}$.

7. Hopper RA, Gruss JS. Greenfield's Surgery: Scientific principles and practice. Philadelphia: Lippincott Williams \& Wilkins; 2006. 389-95 p.

8. Fox LA, Vannier MW, West OC, Wilson AJ, Baran GA, Pilgram TK. Diagnostic performance of CT, MPR and 3DCT imaging in maxillofacial trauma. Computerized medical imaging and graphics : the official journal of the Computerized Medical Imaging Society. 1995;19(5):385-95.

9. Tsiklakis K, Donta C, Gavala S, Karayianni K, Kamenopoulou V, Hourdakis CJ. Dose reduction in maxillofacial imaging using low dose Cone Beam CT. European journal of radiology. 2005;56(3):4137.

10. Chen JY, Liang BL, Liu QY, Hu HJ, Zeng WK, Li JT. [Diagnostic value of multi-slice spiral CT three dimensional reconstruction in maxillofacial diseases]. Zhongguo yi xue ke xue yuan xue bao Acta Academiae Medicinae Sinicae. 2006;28(1):1620. 
11. Fort RL. Experimental Study of Fractures of the Upper Jaw. J Am Soc Plastic Surg. 1972;50:497506.

12. Dos Santos DT, Costa e Silva AP, Vannier MW, Cavalcanti MG. Validity of multislice computerized tomography for diagnosis of maxillofacial fractures using an independent workstation. Oral surgery, oral medicine, oral pathology, oral radiology, and endodontics. 2004;98(6):715-20.

13. Larheim TA, Westesson PL. Maxillofacial Imaging. NewYork: Springer; 2006. 199-226 p.
14. Kau CH, Bozic M, English J, Lee R, Bussa H, Ellis RK. Cone-beam computed tomography of the maxillofacial region--an update. The international journal of medical robotics + computer assisted surgery : MRCAS. 2009;5(4):366-80.

15. Bartling SH, Majdani O, Gupta R, Rodt T, Dullin C, Fitzgerald PF, et al. Large scan field, high spatial resolution flat-panel detector based volumetric CT of the whole human skull base and for maxillofacial imaging. Dento maxillo facial radiology. 2007;36(6):317-27. 